УДК 621.74

DOI 10.36910/6775-2313-5352-2020-17-23

${ }^{1}$ Чернета О.Г., к.т.н., доц., ${ }^{1}$ Сасов О.О., к.т.н., доц., ${ }^{1}$ Шматко Д.З., к.т.н., доц., ${ }^{1}$ Аверянов

В.С., к.т.н., доц.

${ }^{1}$ Дніпровський державний технічний університет

\title{
ПОВЕРХНЕВИЙ ШАР ДЕТАЛІ ІЗ СТАЛІ 45 ПІСЛЯ ЗМЦЦЕННЯ БОРУВАННЯМ І ЛАЗЕРНОЇ ОБРОБКИ
}

В роботі досліджені технології обробки і зміцнення поверхневого шару деталей із сталі 45, що на першому етапі передбачають відновлення геометрії поверхні, борування $і$ лазерну обробку борованого шару. Проведений аналіз структуроутворення пошарових зон в залежності від технологічних методів обробки, розроблена методика визначення параметрів мікротвердості, пружності, коефіиієнту пластичності відповідних локальних зон за допомогою приладу “Micron-gатта". Проведені дослідження фізико-механічних властивостей робочих шарів і мікротвердості. За результати проведених досліджень на відповідних зразках деталей із сталі 45 отримані зображення мікроструктур робочих поверхонь, приведені таблиці і графіки розподілу мікротвердості поверхневого шару деталі. Представлені результати доводять про доцільність використовування розроблених технологій відновлення $i$ зміинення широкого спектру деталей із сталі 45 у машинобудуванні.

Ключеві слова: зносостійкість, відновлення деталей, технологічні способи обробки, металографічні дослідження, робочі поверхні, деталі, мікроструктура.

\section{Постановка проблеми.}

Розвиток виробництва в умовах ринкової економіки не можливий без вирішення проблем підвищення якості і конкурентоспроможності виготовляємих машин. Показник якості машини - це кількісна характеристика одного або декілька іiі властивостей, що розглядається безпосередньо до визначених умов виготовлення і експлуатації даної машини. Для оцінки якості машин застосовують одиничні і комплексні показники. Суттєвий вплив на якість виробів оказують властивості матеріалів, що застосовують при виготовленні деталей. Властивості матеріалів поділяють на механічні, технологічні, хімічні, структурні i експлуатаційні. При масовому виробництві сучасних автомобілів, спостерігається суттєве збільшення потужності, швидкісних режимів експлуатації і як наслідок підвищення вимог до деталей, що працюють в тяжких умовах експлуатації. Використання дефіцитних компонентів для виготовлення легованих і високолегованих сталей значно підвищує собівартість матеріалу. В той же час при виготовленні деталей перспективним напрямом $\epsilon$ подальше використання деталей із сталі 45 [1-3]. При відповідних способах обробки поверхневого шару можливо підвищити в 3-4 рази зносостійкість і корозійну стійкість деталей за рахунок модифікації їх поверхневого шару і трансформації мікроструктури, суттєво підвищити ресурс деталей, знизити собівартість виготовлення деталей, витрати коштовних матеріалів при збереженні якісних i фізико-механічних характеристик, показників надійності, довговічності i зносостійкості.

Комплексне вирішення проблем формування поверхневого шару деталей автомобілів недостатньо досліджене і потребує суттєвого доопрацювання.

Метою роботи $є$ дослідження процесів зносу i розробка технологічних способів відновлення і зміцнення робочих поверхневих шарів деталей автомобілів, виготовлених із сталі 45.

Сучасні технології обробки деталей дозволяють керувати фізико - механічними властивостями і структуро утворенням в матеріалах машинобудівного призначення. Зміцнення поверхневого шару сталей здійснюється шляхом різних варіантів обробок і їх комбінацій, що передбачають утворення в поверхневому шарі міцних і надміцних структур. Використовуючи новітні технології зміцнення сталей $є$ можливість збільшити в рази мікротвердість робочих поверхонь деталей за рахунок керування фізико - механічними властивостями і утворення відповідних надміцних мікроструктур.

В табл.1 наведений хімічний склад, основні характеристики i фізико механічні властивості сталі 45 при звичайних, традиційних методах термічної, хіміко - термічної, термо механічної обробки.

(C) Чернета О.Г., к.т.н., доц., Сасов О.О., к.т.н., доц., Шматко Д.З., к.т.н., доц., Аверянов В.С., к.т.Н., доц. 
Таблиця 1

Хімічний склад, основні характеристики і фізико механічні властивості середньо вуглецеві сталі - Ст 45

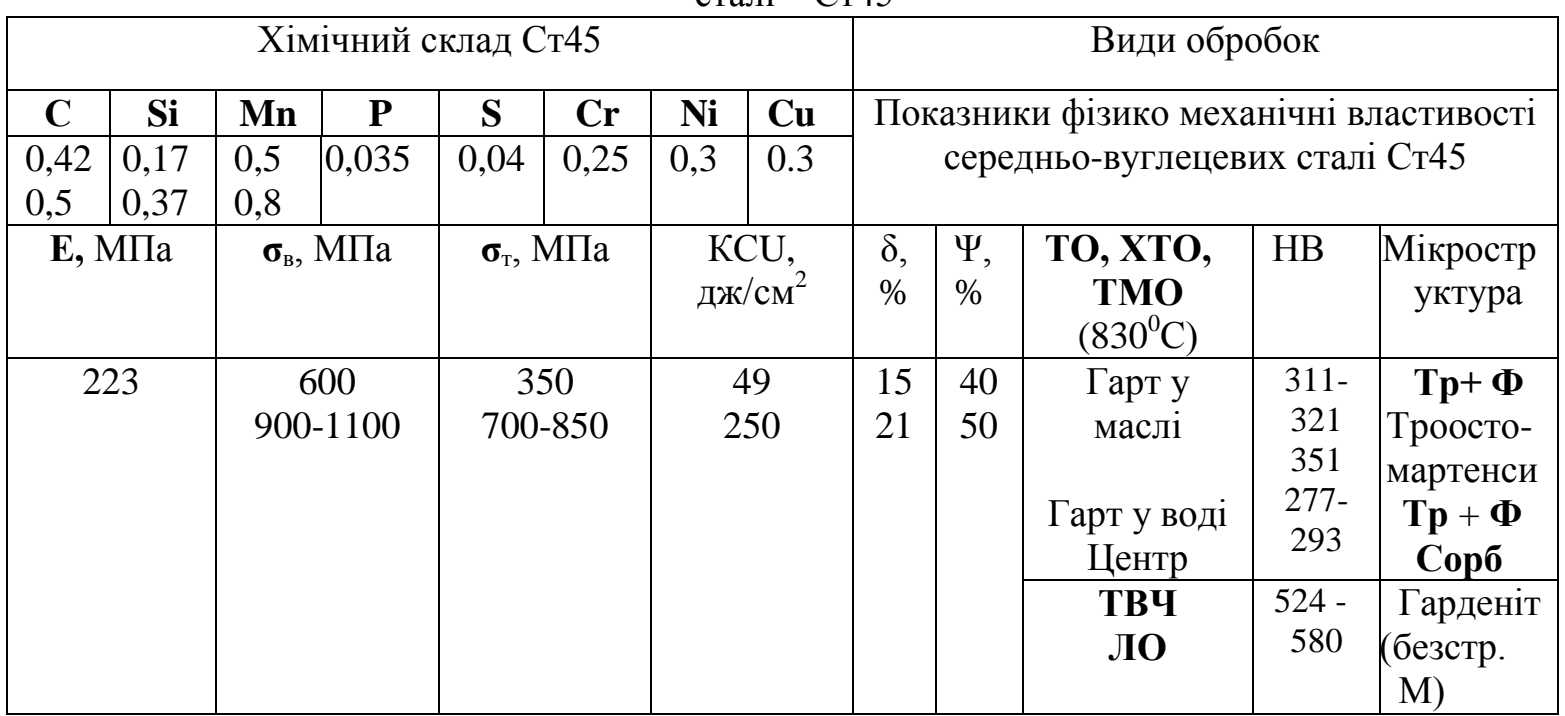

За даними [1], [2] (таблиця 1) наданий хімічний склад середньо - вуглецевої сталі 45. Мікроструктура сорбіту характерна для Ст 45 після нормалізації. При гарті 3 високим відпуском для середньо вуглецевої сталі Ст 45 характерна структура сорбіту з окремими колоніями фериту з твердістю НВ $250-310$.

При гарті в маслі і гарті з середнім відпуском мікроструктури Ст 45 - сприяє утворенню трооститу з феритом.

Гарт у воді і гарт з низьким відпуском сприяє утворенню мікроструктури мартенситу безструктурного мартенситу (гарденіту [3]) (Ст45 НВ 524-580 - гарт ТВЧ, ЛО).

Подальше збільшення мікротвердості поверхневого шару середньо вуглецевих сталей можливо тільки за рахунок використання спеціальних обробок з скупченню у поверхневих шарах надтвердих утворень (карбідів, карбонітридів, нітридів, боридів металів $\mathrm{Fe}_{2} \mathrm{~B}, \mathrm{FeB}$, $\left.\mathrm{Mn}_{7} \mathrm{C}_{3}, \mathrm{Cr}_{7} \mathrm{C}_{3},(\mathrm{Fe}, \mathrm{Cr})_{7} \mathrm{C}_{3}, \mathrm{Me}_{7}(\mathrm{CN})_{3}, \mathrm{Fe}_{3} \mathrm{~N}\right)$.

Це можливо за рахунок використання комбінованих і спеціальних способів обробки (цементація, азотування, борування, лазерна обробка, ІПА, ТВЧ та т.п.). Мікротвердість поверхневих шарів (150 - 200 мкм) середньо вуглецевих сталей при застосуванні перелічених способів обробки збільшується до $\mathrm{H}_{\mu}=13000$ - 17000 МПа при боруванні і ЛО [4], [5]. Разом 3 підвищенням показників мікротвердості, зносостійкості значно погіршуються показники фізико механічних властивостей - пластичності, коефіцієнти збільшення $\delta(\%)$, стиснення $\psi(\%)$,

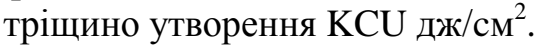

Боридний шар має характерну текстуру (рис.1) - голчастий шар з мікротвердістю до18000 МПа на сталі 45. Текстура, що утворюється в результаті сумісної дифузії бору і вуглецю карбіди, бориди, карбобориди, перешкоджають дифузійним процесам. На рис. 1. під зоною борованого шару $з$ голчастою структурою надана деталізоване зображення борованого перліту 3 напівзруйнованими цементит ними пластинами. Перліт, що початково існує в сталі до дифузійного насичення увесь піддався фрагментації, а новоутворені пластини перліту вистроєні вздовж лінії градієнту концентрації і в значної мірі фрагментації не підверглися. [2]. На рисунку 1 надана мікроструктура поверхні деталі із сталі 45 після борування [3-5].

Поверхневий шар після борування і лазерної обробки після вимірювання мікротвердості показав значення в межах $\mathrm{H}_{\mu}=15000-16000$, МПа. Лазерна обробка сприяла подрібленню зубчастої структури поверхні, що позитивно впливає на усунення негативного моменту тріщино утворення у надтвердих структурах борованого шару.

На рис. 2. наведена мікроструктура поверхневого шару сталі 45 після борування і лазерної обробки. Поверхня сталі 45 визначається щільним шаром надтвердих утворень ( $\mathrm{h}=20$ - 40 мкм). Під цим шаром спостерігається скупчення ( $\mathrm{h}=40-120$ мкм боридів і окремих карбидів).

(C) Чернета О.Г., к.т.н., доц., Сасов О.О., к.т.н., доц., Шматко Д.З., к.т.н., доц., Аверянов В.С., к.т.Н., доц. 


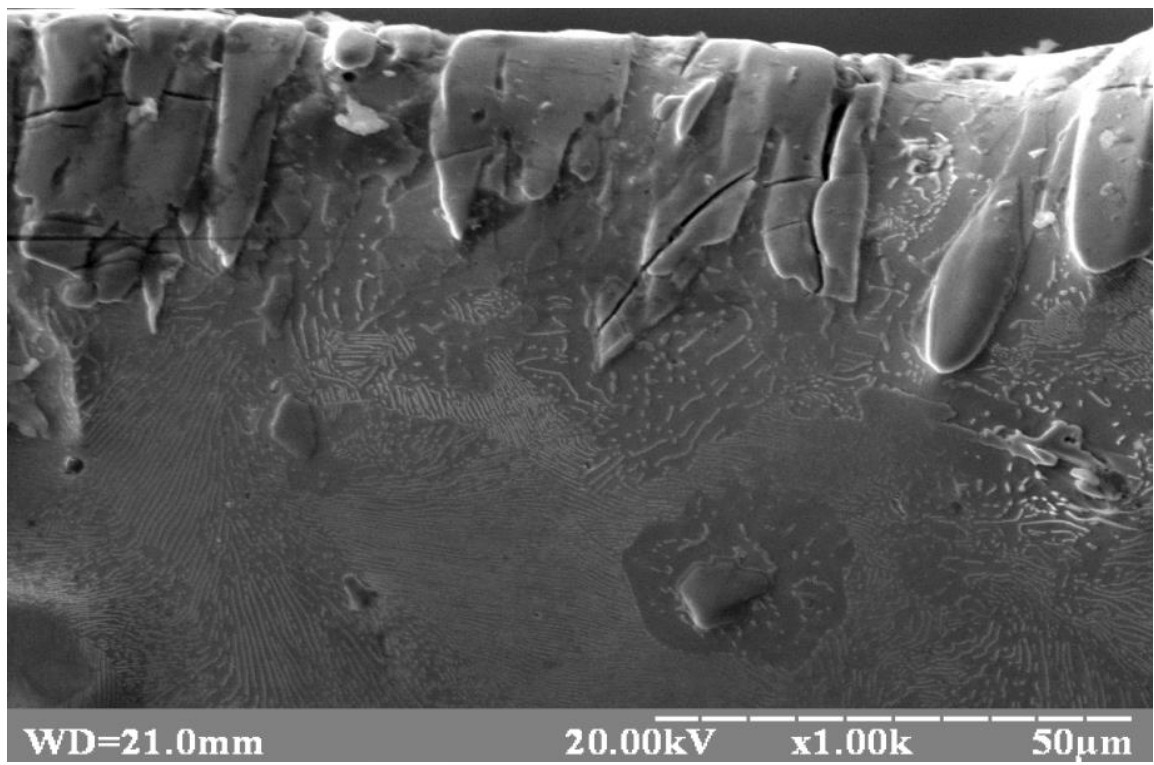

Рис.1. Мікроструктура поверхні деталі із сталі 45 після борування

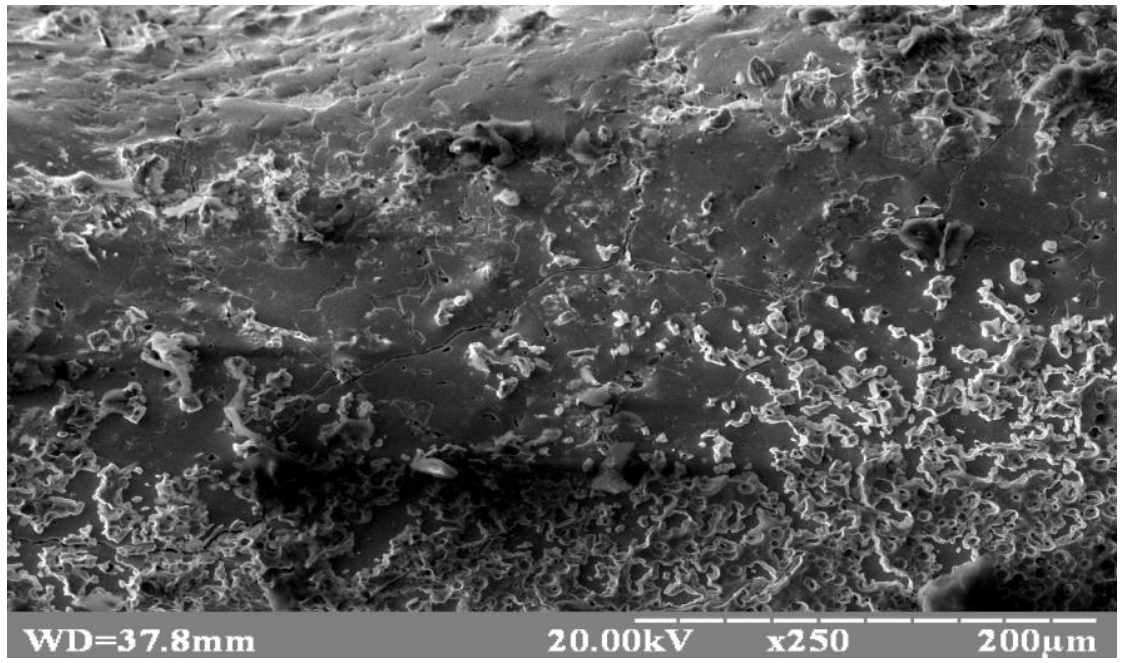

Рис. 2. Мікроструктура поверхневого шару сталі 45 після борування і лазерної

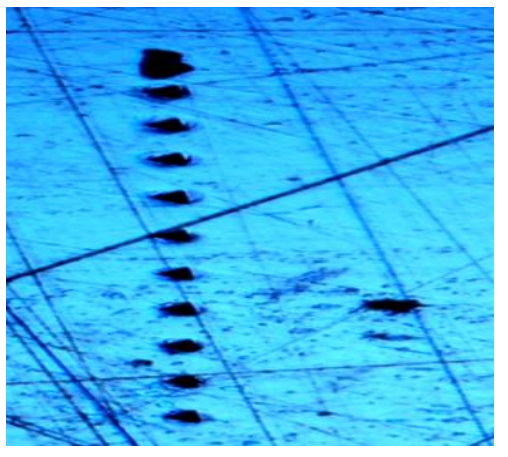

а. №1 - сталь 45 без обробки

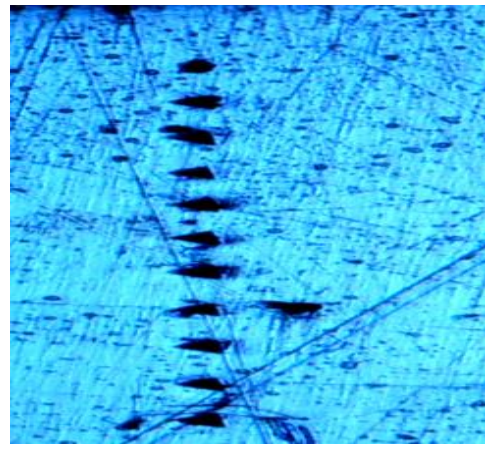

б. №1 - сталь 45 з

боруванням і ЛО

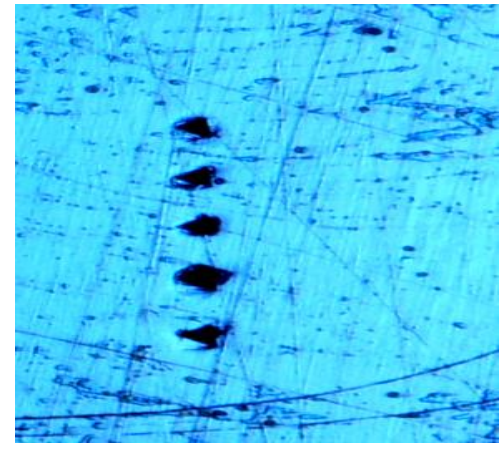

в. №1 - сталь 45 з

боруванням і ЛО (центр)

Рис. 3. Фотографії печатків з трасою сканування

Для дослідження були вибрані фрагменти матеріалів із сталі 45 без обробки, з обробкою шляхом борування і ЛО (поверхневий шар і центр зразка). Уколи (10 точок проникнення індентору) дослідних зон проводили з кроком 50 мкм за допомогою приладу "Micron-gamma", що дозволило за вище наданою методикою визначити параметри мікротвердості, пружності, коефіцієнту пластичності відповідних локальних зон (рис. 3) [6-8].

(C) Чернета О.Г., к.т.н., доц., Сасов О.О., к.т.н., доц., Шматко Д.З., к.т.н., доц., Аверянов В.С., к.т.н., доц. 
На рис.4 наведені результати вимірювань (а. №1 - сталь 45 без обробки, б. №2 - сталь 453 боруванням і ЛО (поверхня), в. №3 - сталь 45 з боруванням і ЛО (центр)) на приладі “Microngamma”.

\begin{tabular}{|c|c|c|c|c|c|c|c|c|c|c|c|c|c|c|c|}
\hline \multirow{2}{*}{\multicolumn{9}{|c|}{ † Таблица расчетов }} & \multirow{2}{*}{\multicolumn{6}{|c|}{ а. №1 - сталь 45 без обробки }} & \multirow{3}{*}{$\underline{\mathbf{x}}$} \\
\hline & & & & & & & & & & & & & & & \\
\hline $\mathrm{N}^{2}$ & P.rp. & V.rp/c & T.c. & h1.mkm & ho,mkm & h2.mkm & H(Mартел) & Нн(Мей: & Iер] H(Мейер) & E.GPa & A06 & Ayn & s (пласт) & К пласт & \\
\hline 1 & 49,2 & 5.0 & 0 & 1.990 & 1,662 & 1.185 & 5,480 & 5.071 & 7.273 & 116,2 & 35.29 & 11.56 & 0.672 & 0.771 & 1,342 \\
\hline 2 & 49,5 & 5,0 & 0 & 2,082 & 1.824 & 1,502 & 5,150 & 4.657 & 6,067 & 135,5 & 37,96 & 9.73 & 0.744 & 0.832 & 1.232 \\
\hline 3 & 49,4 & 5,0 & 0 & 2,038 & 1,809 & 1.516 & 5.631 & 4.852 & 6,157 & 153.7 & 38,92 & 8.66 & 0.778 & 0,855 & 1.284 \\
\hline 4 & 49,4 & 5.0 & 0 & 2,236 & 2,012 & 1.595 & 4,415 & 4.029 & 4,976 & 141,2 & 40,31 & 8.50 & 0.789 & 0.863 & 1,066 \\
\hline 5 & 49.3 & 5.0 & 0 & 2,050 & 1.820 & 1.562 & 5,517 & 4,788 & 6,075 & 151,8 & 38,84 & 7.97 & 0.795 & 0.854 & 1.267 \\
\hline 6 & 49,1 & 5.0 & 0 & 2,085 & 1.893 & 1.624 & 5,360 & 4.612 & 5,591 & 174.8 & 39,67 & 7.55 & 0.810 & 0.882 & 1.220 \\
\hline 7 & 48.9 & 5,0 & 0 & 2,090 & 1.879 & 0,000 & 5.221 & 4,568 & 5.651 & 159,0 & 38,96 & 7,91 & 0.797 & 0,868 & 1,209 \\
\hline 8 & 49,2 & 5.0 & 0 & 2.035 & 1.837 & 1.444 & 5.526 & 4.843 & 5.943 & 174.2 & 38.07 & 7.29 & 0,809 & 0.872 & 1.281 \\
\hline 9 & 50.0 & 5,0 & 0 & 2,128 & 1.948 & 1,702 & 5,043 & 4,509 & 5,376 & 184,6 & 39,68 & 7,22 & 0.818 & 0.887 & 1,193 \\
\hline 10 & 49,3 & 5,0 & 0 & 2,166 & 1,977 & 1.290 & 4,820 & 4.290 & 5,150 & 170.2 & 40,00 & 7.03 & 0.824 & 0.884 & 1.135 \\
\hline
\end{tabular}

1) Таблица расчетов

$P=50,0 \mathrm{~V}=5,00 \mathrm{~T}=0 \mathrm{~S}=0$

б. №2 - сталь 45 з боруванням і ЛО (поверхня)

\begin{tabular}{|c|c|c|c|c|c|c|c|c|c|c|c|c|c|c|c|}
\hline $\mathrm{N}^{2}$ & $P, r p$ & V.rp/c & T,c. & h1,mkm & he,mkm & $\mathrm{h} 2, \mathrm{mkm}$ & H(Мартел & 1) Нr(Mейер & H. (Mейер] & $\mathrm{E,GPa}$ & A.6 & Ayn & s (пласт) & K пласт & Hanp \\
\hline 1 & 50,0 & 5,0 & 0 & 2,407 & 2,200 & 1,942 & 3,965 & 3,523 & 4,218 & 141,5 & 45,17 & 9,07 & 0,799 & 0,885 & 0,932 \\
\hline 2 & 50,0 & 5,0 & 0 & 2,584 & 2,410 & 2,182 & 3.547 & 3,057 & 3,513 & 154,3 & 49,98 & 8,03 & 0,839 & 0.913 & 0,809 \\
\hline 3 & 50,0 & 5,0 & 0 & 2,379 & 2,183 & 1,942 & 4,242 & 3,605 & 4,284 & 150,2 & 46,68 & 8,37 & 0,821 & 0,895 & 0,954 \\
\hline 4 & 50,0 & 5,0 & 0 & 2,691 & 2,525 & 2,347 & 3,083 & 2,819 & 3,201 & 154,0 & 49,07 & 7,11 & 0,855 & 0,916 & 0,746 \\
\hline 5 & 50,0 & 5,0 & 0 & 2,668 & 2,491 & 2,279 & 3,390 & 2,867 & 3,288 & 146,2 & 52,62 & 7,42 & 0,859 & 0.916 & 0,758 \\
\hline 6 & 50,0 & 5,0 & 0 & 2,702 & 2,531 & 2,338 & 3,172 & 2,796 & 3,186 & 149,1 & 51,11 & 7,23 & 0,858 & 0,916 & 0.740 \\
\hline 7 & 50,0 & 5,0 & 0 & 2,430 & 2,249 & 1,996 & 4,131 & 3,457 & 4,033 & 159,0 & 48,40 & 7,54 & 0,844 & 0,907 & 0,915 \\
\hline 8 & 50,0 & 5,0 & 0 & 2,656 & 2,492 & 2,287 & 3,375 & 2,894 & 3,287 & 158.0 & 51,64 & 7,15 & 0,861 & 0,921 & 0,766 \\
\hline 9 & 50,0 & 5.0 & 0 & 2,523 & 2,348 & 2,153 & 3,694 & 3,205 & 3.701 & 156,6 & 48,49 & 7,52 & 0,845 & 0.910 & 0.848 \\
\hline 10 & 50,0 & 5,0 & 0 & 2,600 & 2,434 & 2,194 & 3,665 & 3,019 & 3,446 & 159,3 & 52,62 & 7,07 & 0,866 & 0,921 & 0,799 \\
\hline
\end{tabular}

\section{\Таблица расчетов}

$P=50,0 \mathrm{~V}=5,00 \mathrm{~T}=0 \mathrm{~S}=0$ в. №3 - сталь 45 з боруванням і ЛО (центр)

\begin{tabular}{|c|c|c|c|c|c|c|c|c|c|c|c|c|c|c|c|}
\hline$N^{2}$ & P. гр. & V,rp/c & $T, c$ & h1,mkm & he,mkm & h2,mkm & H(Мартел) & Нн(Мейер & 3. H(Meйep) & $\mathrm{E}, \mathrm{GPa}$ & A.6 & Ayn & s (пласт) & K пласт & Hanp. GF \\
\hline 1 & 48,9 & 5,0 & 0 & 2,208 & 2,012 & 0,476 & 4,862 & 4,095 & 4,929 & 160,3 & 42,75 & 7,74 & 0,819 & 0,888 & 1,084 \\
\hline 2 & 50,0 & 5,0 & 0 & 2,378 & 2,190 & 1,927 & 4,081 & 3,610 & 4,254 & 157,1 & 44,82 & 7,91 & 0,824 & 0,896 & 0,955 \\
\hline 3 & 50,0 & 5,0 & 0 & 2,349 & 2,172 & 1,961 & 4,144 & 3,700 & 4,328 & 167,7 & 43,86 & 7,64 & 0,826 & 0,899 & 0,979 \\
\hline 4 & 50,0 & 5,0 & 0 & 2,759 & 2,594 & 2,377 & 2,989 & 2,681 & 3,032 & 150,9 & 51,29 & 6,57 & 0,872 & 0,920 & 0,709 \\
\hline 5 & 50,0 & 5,0 & 0 & 2,531 & 2,362 & 2,196 & 3,683 & 3,186 & 3,659 & 161,3 & 48,78 & 6,77 & 0,861 & 0,913 & 0,843 \\
\hline
\end{tabular}

Рис.4. Результати вимірювань на приладі "Micron-gamma"

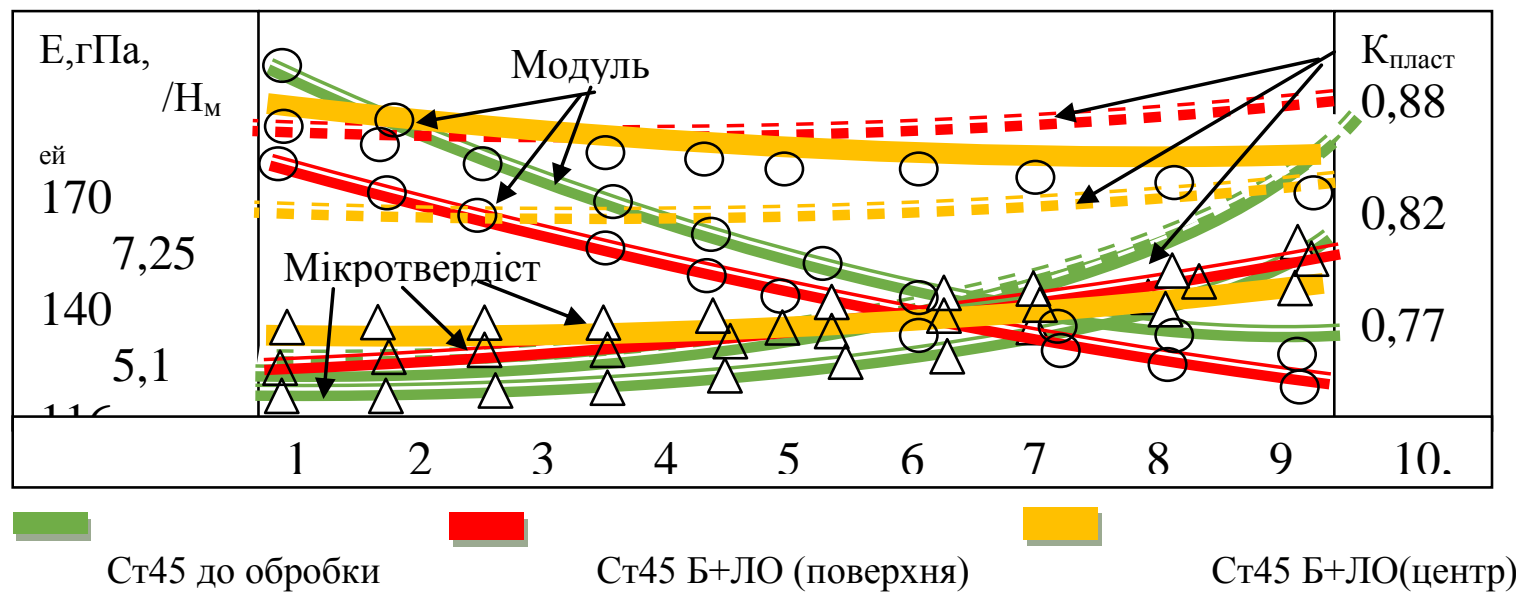

Рис.5. Графічні залежності вимірів мікротвердості, модуля пружності і коефіцієнта пластичності на різних ділянках дослідних сталей

При скануванні поверхні на сталі 45 без обробки модуль пружності коливається від 116 до 170 гПа, а при боруванні поверхні з наступною лазерною обробкою від 141 до 159 гПа, а в центрі 160-161 гПа. Розкид показників мікротвердості коливається від $\mathrm{H}_{\text {мей }}=5.15-7,23$ і для оброблених поверхней $\mathrm{H}_{\text {мей }}=3,4-4,6$. Коефіціснт пластичності для необробленої поверхні

(с) Чернета О.Г., к.т.н., доц., Сасов О.О., к.т.н., доц., Шматко Д.З., к.т.н., доц., Аверянов В.С., К.Т.н., доц. 
складає 0,7-0,8, для борованих поверхней з лазерною обробкою 0,8-0,9 [9-11].

Висновки. На підставі аналізу ряду застосованих існуючих технологічних способів зміцнення поверхневого шару і при суттєвому збільшенні мікротвердості поверхневих шарів виникає небезпечність внутрішнього руйнування матеріалу (при збільшенні межі витривалості і текучості, знижується пластичні показники і знижується опір крихкому руйнуванні. Детально досліджена структура борованого шару i фазовий склад на сталі 45 після дифузійного насичення бором і лазерної обробки. Умовно виділено наступні зони: - поверхневий шар повністю складається 3 боридів заліза $\mathrm{Fe}_{2} \mathrm{~B}$ i $\mathrm{FeB}$; - другий шар містить залишки боридів заліза $\mathrm{Fe}_{2} \mathrm{~B}$ i $\mathrm{FeB}, a$ - фазу і карбобориди $\mathrm{Fe}_{3}(\mathrm{C}, \mathrm{B})$ і $\mathrm{Fe}_{23}(\mathrm{C}, \mathrm{B})_{6}$; - третій шар містить залишки боридів заліза $\mathrm{Fe}_{2} \mathrm{~B}$ і $\mathrm{FeB}$. Бор в цьому шарі міститься в карбоборидах; - четвертий шар зберігає вихідну ферітно-перлітну структуру сталі 45.

\section{Список літератури}

1. Суслов А.Г., Браун Э.Д., Виткевич Н.А. Качество деталей машин. Справочник. Т.1. М: Машиностроение, 1995. - 143с.

2. Франценюк И.В., Франценюк Л.И. Альбом микроструктур чугуна, стали, цветных метал лов и их сплавов. -М.:ИКЦ «Академкнига», 2004. -136с.

3. Завьялов А.С., Теплухин Г.Н., Габєєв К.В. Умови і механізм утворення безструктурного мартенсіту (гарденита). Металознавство і термічна обробка металів.- №10.-1979.С.11-12.

4. Боровинская И.П. Образование тугоплавких соединений при горении гетерогенных, конденсированных систем. В кн.: Горение и взрыв. Матер. IV Bcec. симпоз. по горению и взрыву. М.: Наука, 1977, с. 138- 148.

5. Иванов С.Г., Дон Яджи, Гурьев А.М. Микроструктура диффузионной зоныстали 3 после совместного диффузионного насыщения бором и хромом. //Ползуновский альманах №4.- 2016. -C. 5-7

6. Ігнатович С.Р., Закиев И.М. Универсальный микро нано - индентометр «MicronGamma». Заводская лаборатория. - 2011. - Т. 77, № 1. - С. 61-67.

7. ISO/FDIS 14577-1: 2002; Metallic materials - Instrumented indentation test for hardness and materials parameters. Part 1: Test method - Geneva: ISO Central Secretariat, 2002.

8. Чернета О.Г., Сухомлин В.І., Коробочка О.М. Дослідження мікроструктури зношених деталей автомобілів із сталі 45 при відновлені і багатократній термічній обробці. Перспективні технології та прилади. м. Луцьк червень 2017 р. -ЛНТУ, - Вип.10(1) - 2017. C.212-217.

9. Чернета О.Г., Волощук Р.Г., Коробочка О.М. Дослідження технологічних способів формування зносостійких покриттів на основі лазерної обробки. / / Збірник наукових праць «Перспективні технології та прилади»//м. Луцьк листопад 2014 р. - Луцьк: ЛНТУ, - Вип.5(2) 2014. C.176.

10. Чернета О.Г., Кубіч В.І., Коржавін Ю.А. Дослідження механічних характеристик деталей із сталі 45 методом інструментального індентирування. INNOVATIVE DEVELOPMENT OF SCIENCE AND EDUCATION. Abstracts of I International Scientific and Practical Conference, March 29-31, GREECE, Athens, 2020. -P.219-225.

11. Чернета О.Г., Кубіч В.І., Коржавін Ю.А. Дослідження фізико-механічних характеристик деталей із сталі 45 методами динамічного втиснення індентору, склерометрії і мікротрибології . MODERN SCIENCE: PROBLEM AND INNOVATIONS. Abstracts of I International Scientific and Practical Conference, April 5-7, SWEDEN, Stockholm, 2020. -P.290-296.

\footnotetext{
${ }^{1}$ Cherneta O.G., ${ }^{1}$ Sasov O.O., ${ }^{1}$ Shmatko D.Z., ${ }^{1}$ Averyanov V.S.

${ }^{1}$ Dniprovsk State Technical Univercity
}

\section{SURFACE LAYER STEEL DETAILS 45 AFTER STRENGTHENING BY BORING AND LASER TREATMENT}

The technologies of processing and strengthening of the surface layer of details from steel 45 are investigated in the work, which at the first stage provide restoration of surface geometry, drilling and laser processing of the drilled layer. The analysis of structure formation of layered zones depending on technological methods of processing is carried out, the technique of definition of parameters of microhardness, elasticity, coefficient of plasticity of the corresponding local zones by

(С) Чернета О.Г., к.Т.н., доц., Сасов О.О., к.т.н., доц., Шматко Д.З., к.т.н., доц., Аверянов В.С., к.т.н., доц. 
means of the device "Micron-gamma" is developed. Researches of physical and mechanical properties of working layers and microhardness are carried out. According to the results of the research on the corresponding samples of parts made of steel 45, images of the microstructures of the working surfaces are obtained, tables and graphs of the distribution of the microhardness of the surface layer of the part are given. The presented results prove the expediency of using the developed technologies of restoration and strengthening of a wide range of steel parts 45 in mechanical engineering.

Key words: wear resistance, restoration of details, technological methods of processing, metallographic researches, working surfaces, details, microstructure.

\footnotetext{
${ }^{1}$ Чернета О.Г., ${ }^{1}$ Сасов О.О., ${ }^{1}$ Шматко Д.3., ${ }^{1}$ Аверьянов В.С.

${ }^{1}$ Днепровский государственный технический университет
}

\section{ПОВЕРХНОСТНЫЙ СЛОЙ ДЕТАЛИ ИЗ СТАЛИ 45 ПОСЛЕ УПРОЧНЕНИЯ БОРИРОВАНИЕМ И ЛАЗЕРНОЙ ОБРАБОТКИ}

В работе исследованы технологии обработки и упрочнения поверхностного слоя деталей из стали 45, что на первом этапе предусматривает восстановление геометрии поверхности, борирования и лазерную обработку борированного слоя. Проведенный анализ структурообразования послойных зон в зависимости от технологических методов обработки, разработана методика определения параметров микротвердости, упругости, коэффициента пластичности соответствующих локальных зон с помощью прибора "Micron-gaтта". Проведенны исследования физико-механических свойств рабочих слоев и микротвердости. По результатам проведенных исследований на соответствующих образиах деталей из стали 45 полученны изображения микроструктур рабочих поверхностей, приведены таблицы и графики распределения микротвердости поверхностного слоя детали. Представлены результаты доказывают о иелесообразности использования разработанных технологий восстановления $и$ укрепления широкого спектра деталей из стали 45 в машиностроении.

Ключевые слова: износостойкость, восстановление деталей, технологические способь обработки, металлографические исследования, рабочие поверхности, детали, микроструктура.

(С) Чернета О.Г., к.т.н., доц., Сасов О.О., к.т.н., доц., Шматко Д.З., к.т.н., доц., Аверянов В.С., к.Т.н., доц. 